\title{
Armazenamento de sementes de crambe tratadas com inseticidas ${ }^{1}$
}

\section{Storage crambe seed treated with insecticides}

\author{
Geraldo Cabral e Souza ${ }^{2 *}$; Juliana de Fátima Sales ${ }^{3}$; Fabiano Guimarães Silva ${ }^{3}$; \\ Márcio Fernandes Peixoto ${ }^{3}$; Rafael Vieira Barbosa ${ }^{4}$
}

\section{Resumo}

O uso de sementes de baixa qualidade, com um menor potencial fisiológico, reflete numa das principais causas da baixa produtividade. Sendo assim as condições de armazenamento de sementes devem ser levadas em consideração. Esta pesquisa teve por objetivo avaliar a influência de inseticidas naturais e sintéticos na emergência e no armazenamento de sementes de crambe, já que tais sustâncias são indispensáveis para evitar a infestação das sementes de outras espécies por organismos nocivos. $\mathrm{O}$ delineamento experimental foi em blocos ao acaso, no esquema fatorial $8 \times 3$ (8 substâncias e 3 tempos de armazenamento), com 4 repetições. Avaliaram-se os seguintes inseticidas naturais: açafrão, calcário, cinza, nim, terra de diatomáceas; e sintéticos: clorpirifós e deltametrina; além do tratamento controle, constituído de sementes sem qualquer tipo de tratamento. Avaliaram-se a porcentagem de emergência, o índice de velocidade de emergência e tempo para atingir 50\% da emergência. Em todas as características avaliadas, constatou-se nenhuma influência do nim sobre o vigor das sementes. Verificouse desvantagens na aplicação dos inseticidas clorpirifós e terra de diatomáceas, que interferiram na velocidade de emergência das sementes de crambe. As sementes tratadas com os demais inseticidas tiveram comportamento diferenciado das sementes não tratadas após os 120 dias de armazenamento ao avaliar o tempo que as mesmas demoram a atingir $50 \%$ de emergência.

Palavras-chave: Tratamento de sementes, emergência, qualidade fisiológica

\begin{abstract}
The use of low quality seeds with a lower physiological reflects one of the major causes of low productivity. Thus the storage conditions of seed must be taken into consideration. This research aimed to evaluate the influence of natural and synthetic insecticides on emergence and seed storage of crambe, as these substances are essential to prevent infestation of seeds of other species by harmful organisms. The experimental design was a randomized block in factorial 3 × 8 ( 8 substances and 3 storage times ) with 4 replications. We assessed the following natural insecticides: saffron, lime, ash, neem, diatomaceous earth, and synthetic: chlorpyrifos and deltamethrin; besides the control consisting of seeds without any treatment. We evaluated the percentage of emergence, speed of emergence index and time to reach $50 \%$ of emergency. In all characteristics, it was found that no influence of neem on seed vigor. There are disadvantages in the application of the insecticides chlorpyrifos and diatomaceous earth, which interfered with the emergence rate of seeds of crambe. The seeds treated with other insecticides had different behavior of untreated seeds after 120 days of storage to assess the time that they take to reach $50 \%$ germination.
\end{abstract}

Key words: Seed treatment, emergency, physiological quality

\footnotetext{
${ }^{1}$ Pesquisa financiada pelo CNPq. Conselho Nacional de Desenvolvimento Científico e Tecnológico.

2 Prof. M.e da Universidade de Rio Verde, FESURV e da Rede Municipal de Educação de Rio Verde, GO. Programa de Pós-Graduação em Ciências Agrárias, Instituto Federal Goiano, IF Goiano, Campus, Rio Verde. Rio Verde, GO. E-mail: gcabralesouza@yahoo. com.br

${ }^{3}$ Profs. Drs. do Instituto Federal de Educação, Ciência e Tecnologia Goiano, Campus Rio Verde, GO. E-mail: juliana.sales@, pq.cnpq.br; fabianocefetrv@yahoo.com.br; marciofpeixoto@gmail.com

${ }^{4}$ Discente de graduação em Ciências Agrárias, IF Goiano, Campus Rio Verde, GO. E-mail: rafaelfera@gmail.com

* Autor para correspondência
} 
O crambe (Crambe abyssinica Hochst), uma cultura de inverno, destaca-se entre as novas fontes oleaginosas para produção de biocombustíveis, pois se trata de uma planta da família das Brassicaceae, de elevada rusticidade e com potencial para produzir cerca de 28 a $30 \%$ de teor de óleo, superando por exemplo a soja, nesta característica (NEVES et al., 2007).

Para que a ampliação da oferta dessa matériaprima seja bem sucedida, é necessário desenvolver um conjunto de conhecimentos que permitam a obtenção de maior qualidade fisiológica e conservação das sementes. Portanto há uma busca pela manutenção da qualidade sanitária das sementes durante o armazenamento. Medidas de higienização, bem como aplicações preventivas com inseticidas organofoforados e piretróides, por exemplo, contribuem para o controle de pragas de grãos armazenados (BENHALIMA et al., 2004).

Vários inseticidas químicos são utilizados no combate de pragas, sendo que atualmente é também comum o uso de inseticidas naturais, em razão da facilidade de obtenção, baixo custo e segurança no manuseio, além de ser mais uma fonte de renda para o pequeno produtor, o que propicia a utilização mais sustentável da pequena propriedade rural.

Entre os inseticidas naturais, o nim (Azadirachta indica A. Juss), é considerada como uma das mais importantes plantas com atividade inseticida em várias partes do mundo (MEDINA et al., 2004). Os múltiplos efeitos positivos de seu óleo no combate de pragas de plantas hospedeiras da família Brassicaceae foram observados, como observações dos parâmetros de comportamento e biologia de Microtheca punctigera em Nabiça (Raphanus raphanistrum L.) (MIKAMI; VENTURA, 2008).

Além do nim, outros extratos e pós de origem vegetal são eficientes no combate contra a infestação de insetos, quando comparados com outros tratamentos químicos, como observado por Previero et al. (2006), em sementes de milho tratadas com açafrão (Curuma longa L) e armazenadas por até oito meses.
Vários tipos de pós inertes também são utilizados como inseticidas naturais, como a terra de diatomáceas, que em armadilhas do tipo de caladores em silos de cevada mostrou-se eficiente na captura de insetos como C. ferrugineus, Sitophilus spp. e $O$. surinamensis (MILLAN et al., 2007).

No entanto aplicação de inseticidas naturais ou químicos pode afetar o potencial fisiológico das sementes dependendo do grau de umidade no momento da aplicação, do produto utilizado e das condições e período de armazenamento (Marcos Filho, 2005). Diante disso, este trabalho teve como finalidade avaliar a influência de inseticidas naturais e sintéticos no vigor de sementes de crambe, em diferentes períodos de armazenamento.

Os experimentos foram conduzidos nos Laboratórios de Sementes e de Entomologia do Instituto Federal de Educação, Ciência e Tecnologia Goiano - Campus Rio Verde.

As sementes de crambe (Crambe abyssinica Hochst) foram obtidas do Centro Tecnológico (CTC) Cooperativa Agroindustrial dos Produtores Rurais do Sudoeste Goiano (COMIGO), colhidas manualmente na segunda quinzena de julho no ano de 2009. Após a colheita foram levadas ao Laboratório de Sementes, onde foram debulhadas. Em seguida, determinou-se o teor de água (12\% b.u.) pelo método de estufa, à $105 \pm 3^{\circ} \mathrm{C}$ durante 24 $\mathrm{h}$, de acordo com as regras para análise de sementes (BRASIL, 2009).

$\mathrm{O}$ delineamento experimental utilizado foi em blocos casualizados em esquema fatorial $8 \times 3$ (8 tratamentos e 3 tempos de armazenamento), com 4 repetições, totalizando 96 unidades experimentais cada uma composta por 50 sementes. Os tratamentos, além do controle, consistiram de sementes tratadas com as seguintes substâncias: açafrão, nim, calcário, cinzas, terra de diatomácea, na forma de pó $(6 \mathrm{~g})$ e, clorpirifós e deltametrina na forma de óleos $(0,15 \mathrm{~mL})$. Foi misturada $300 \mathrm{~g}$ de sementes de crambe com os respectivos tratamentos (as substâncias, inclusive os pós, foram diluídas 
em $5 \mathrm{~mL}$ de água), homogeneizando cada amostra por meio de agitação manual em saco plástico por 2 minutos. Cada amostra foi subdividida em três amostras, sendo a primeira, semeado logo após o tratamento e os demais após 120 e 240 dias de armazenamento em sacos de plásticos (de alta densidade para autoclave), em sala climatizada, na ausência de luz, sendo que a temperatura média do ar foi de $17,8^{\circ} \mathrm{C}$ e umidade relativa (UR) de $60,3 \%$.

As sementes foram semeadas a $1,5 \mathrm{~cm}$ de profundidade em canteiros de emergência com nebulização intermitente. A temperatura média do ar na casa de vegetação foi de $24,2^{\circ} \mathrm{C}$ e umidade relativa (UR) de $81 \%$. As avaliações foram realizadas por meio de contagens diárias do número de plântulas emergidas, as contagens foram utilizadas para determinar o IVE (índice de velocidade de emergência), e T50 (tempo médio para ocorrer $50 \%$ de emergência). Os cálculos de velocidade de emergência foram realizados de acordo com Maguire (1962).

Os dados foram submetidos à análise de variância usando o teste $\mathrm{F}$ até $5 \%$ de probabilidade e as médias foram comparadas utilizando-se o teste de Scott-Knott, adotando-se o nível de 5\% de probabilidade. Tais análises foram realizadas com auxílio do programa estatístico Sisvar.

As sementes de crambe tiveram taxas de germinação inferiores a $50 \%$ (tabela 1). Valores de germinação inferiores à $50 \%$ também já foram encontrados em outros estudos com esta espécie para sementes com pericarpo e maior taxa germinação para as sementes de crambe sem pericarpo com valores próximos a $80 \%$ (NEVES et al., 2007; RUAS et al., 2010). O pericarpo proporciona elevada taxa de desuniformidade de germinação ou mesmo ausência desta.

Tabela 1. Porcentagem de emergência (E), índice de velocidade emergência (IVE) e tempo para atingir $50 \%$ de emergência (T50) de sementes de crambe (Crambe abyssinica Hochst) em função de diferentes inseticidas tempo de armazenamento.

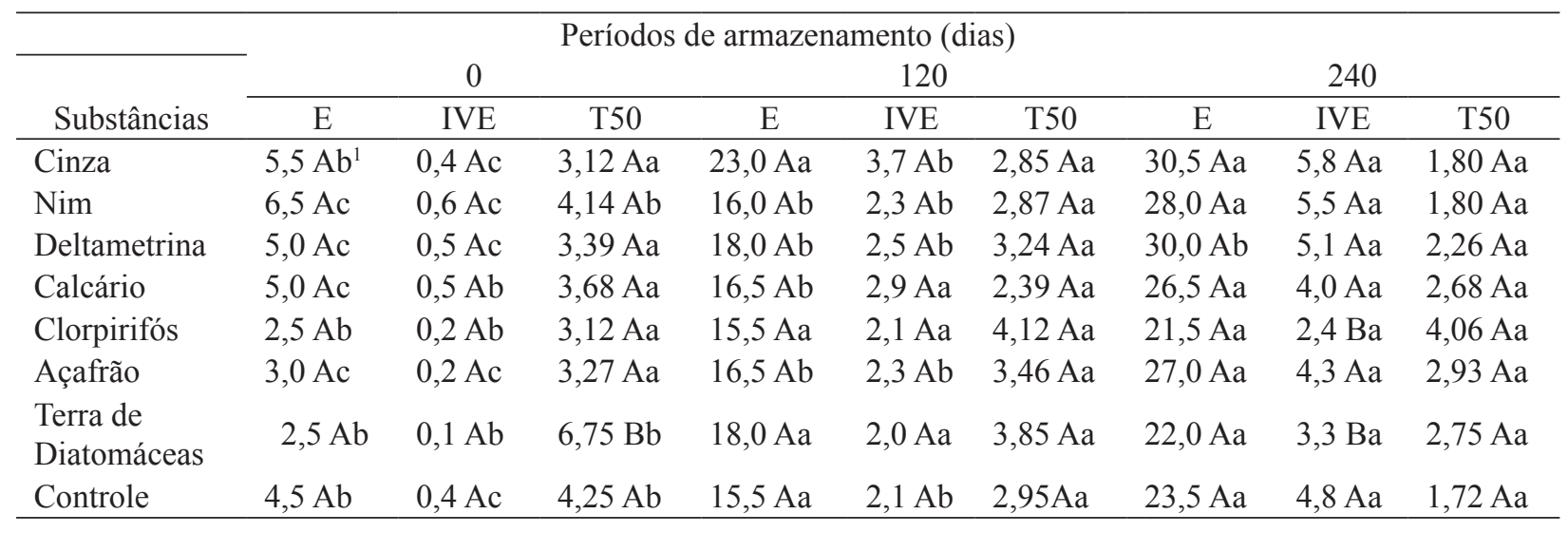

${ }^{1}$ Médias seguidas pela mesma letra, minúscula na linha e maiúscula na coluna não diferem entre si pelo teste de Scott-Knott, a 5\% de probabilidade.

Fonte: Elaboração dos autores.

As substâncias analisadas não exerceram influência na porcentagem de emergência, independente do tempo de armazenamento (Tabela 1). Resultados semelhantes foram obtidos por Rupp et al. (2007), os quais verificaram que sementes de cevada mantiveram o teor mínimo de germinação (92\%) exigido para esta espécie quando tratadas com terra de diatomáceas e deltametrina e armazenadas por 135 dias. 
Em relação à velocidade de emergência, houve interferência negativa das substâncias aplicadas para as sementes tratadas com clorpirifós e terra de diatomáceas. $\mathrm{O}$ índice de velocidade de emergência para estas sementes foi inferior às demais, inclusive o controle, independente do tempo de armazenamento (tabela 1), já que a interação não foi significativa (tabela 2). Paixão, (2009), ao estudar o armazenamento de sementes de milho, também constatou desvantagens no teste de vigor de sementes tratadas com terra de diatomáceas.

Tabela 2. Resumo da análise de variância das variáveis: porcentagem de emergência (E), índice de velocidade emergência (IVE) e tempo para atingir 50\% de emergência (T50) de sementes de crambe (Crambe abyssinica Hochst) em função de diferentes inseticidas e tempo de armazenamento.

\begin{tabular}{|c|c|c|c|c|}
\hline \multirow{2}{*}{ Fontes de Variação } & \multirow{2}{*}{ GL } & $\mathrm{E}$ & IVE & $\mathrm{T} 50$ \\
\hline & & QM & QM & $\mathrm{QM}$ \\
\hline Bloco & 3 & 97.375000 n.s. & $6.665874 * *$ & 1.190434 n.s. \\
\hline Inseticidas & 7 & 52.755952 n.s. & $3.565516 * *$ & $4.251587 * *$ \\
\hline $\mathrm{TA}$ & 2 & $3855.875000 * *$ & $130.206413 * *$ & $17.252820 * *$ \\
\hline $\mathrm{I} \times \mathrm{TA}$ & 14 & 14.255952 n.s. & 1.549652 n.s. & $2.671652 *$ \\
\hline Resíduo & 69 & 37.664855 & 1.136937 & 1.330344 \\
\hline Total & 95 & & & \\
\hline $\mathrm{CV}(\%)$ & & 38,51 & 43,40 & 35,71 \\
\hline
\end{tabular}

GL: graus de liberdade; TA: tempo de armazenamento; I×TA: interação entre inseticidas e tempo de armazenamento; n.s.: não significativo; *: significativo a $5 \% ; * *$ : significativo a $1 \%$.

Fonte: Elaboração dos autores.

Sementes tratadas com terra de diatomáceas quando não armazenadas tiveram tempo para atingir $50 \%$ de emergência maior do que as sementes que não foram tratadas, e as que foram tratadas com clorpirifós, não apresentaram redução para esta característica após 120 dias de armazenamento como aconteceu com as sementes não tratadas (tabela 1).

A redução na velocidade de emergência pode ser devido à presença dos resíduos destes inseticidas em tecidos mais internos da semente. Zayed, Farghaly e El-maghraby (2003), verificaram que resíduos superficiais de clorpirifós em soja armazenada por 30 semanas diminuíram durante o período de armazenamento, enquanto os resíduos em extratos internos aumentaram gradualmente, sendo que foi observado nestes resíduos uma pequena porcentagem de oxigênio-análogo de clorpirifós.

Estes resíduos decorrentes de inseticidas organofosforados são substâncias tóxicas responsáveis pela geração de espécies reativas de oxigênio (TUZMEN et al., 2008). Estes em sementes iniciam uma série de reações degradativas, causando a peroxidação de lipídios e consequentemente danos às membranas e degradação de proteínas, afetando assim a atividade respiratória, tornando a velocidade de germinação mais lenta (MARCOS FILHO, 2005).

A influência desses inseticidas na velocidade de emergência também pode estar relacionada ao processo de embebição, uma vez que os componentes presentes nos mesmos podem afetar o potencial matricial das sementes que durante o armazenamento tenham aumentado sua concentração nos tecidos mais internos das sementes. Como por exemplo, o alumínio, um componente químico presente na terra de diatomáceas, proveniente do metabolismo $\mathrm{Al}_{2} \mathrm{O}_{3}$ (SOUZA, 2003), pode provocar uma redução significativa na germinação de sementes.

As demais substâncias (cinza, deltametrina, 
calcário e açafrão), dentre as três características avaliadas, tiveram comportamento diferenciado do controle apenas no tempo para as sementes atingirem 50\% de emergência, que não reduziu com 120 dias de armazenamento como aconteceu para as sementes não tratadas (controle) (tabela 1). Já o nim, nem mesmo para esta característica, exerceu influência no vigor das sementes, tendo comportamento semelhante ao controle. Neves et al. (2008), também não verificaram influência de pó de folhas de nim na porcentagem de germinação de sementes de maracujá armazenadas em recipientes de plástico transparentes por até 6 meses.

Em todas as características avaliadas observou-se durante o período de armazenamento, um aumento no vigor das sementes de crambe dependendo do inseticida aplicado (tabela 2) ou não (tabela 1). A impressão de aumento do vigor com o tempo de armazenamento ocorre devido aos processos de deterioração do pericarpo que envolve a semente, pois segundo Neves et al. (2007), esta estrutura afeta o processo de germinação de sementes desta espécie.

Enfim, dentre as substâncias estudadas, somente o nim teve comportamento simular ao controle em todas as características avaliadas. Já as demais interferiram na velocidade de emergência comprometendo a qualidade fisiológica da semente, principalmente o clorpirifós e a terra de diatomáceas. No entanto é interessante mais estudos em relação à caracterização e a influência de compostos químicos dessas substâncias sobre os mecanismos fisiológicos relacionados ao processo germinativo de sementes dessa espécie.

\section{Referências}

BENHALIMA, H.; CHAUDHRY, M. Q.; MILLS, K. A.; PRICE, N. R. Phosphine resistance in stored-product insects collected from various grain storage facilities in Marocco. Journal of Stored Products Research, Oxford, v. 40, n. 3, p. 241-249, 2004.
BRASIL. Ministério da agricultura e reforma Agrária. Regras para análise de sementes. Brasília, DF: SNDA/ DNDV/CLAV, 2009. 398 p.

MAGUIRE, J. D. Speed of germination aid in selection and evaluation for seedling and vigour. Crop Science, Madison, v. 2, n. 2, p. 176-177, 1962.

MARCOS FILHO, J. Fisiologia de sementes de plantas cultivadas. Piracicaba: FEALQ, 2005, 495 p.

MEDINA, P.; BUDIA, F.; DEL ESTAL, P.; VINUELA, E. Influence of azadirachtin, a botanical insecticide, on Chrysoperla carnea (Stephens) reproduction: toxicity and ultrastructural approach. Journal of Economic Entomology, Lanham, v. 97, n. 1, p. 43-50, 2004.

MIKAMI, A. Y.; VENTURA, M. U. Repellent, antifeedant and insecticidal effects of neem oil on Microtheca punctigera. Brazilian Archives of Biology and Technology, Curitiba, v. 51 n. 6, p. 1121-1126, 2008.

MILLAN, M. M.; CRUZ, M. E. da S.; SOUZA, S. P. J.; FERREIRA G. da S. S.; FERREIRA, R. B. Efeito inseticida da terra diatomácea em cevada armazenada. Revista Brasileira de Agroecologia, Bahia, v. 2, n. 2, p. 1135-1139, 2007.

NEVES, M. B.; TRZECIAK, M. B.; VINHOLES, P. S.; TILLMANN, C. A. C.; VILLELA, F. A. Qualidade fisiológica de sementes de crambe produzidas em Mato Grosso do Sul. In: SIMPÓSIO ESTADUAL DE AGROENERGIA, 2007, Pelotas. Anais... Pelotas: Embrapa, 2007. p. 97-98. Disponível em: <http:// www.cpact.embrapa.br/ publicações/ download/ livro/ Agroenergia. 2007/Agroener/trabalhos/Outras \%20 culturas_11_OK/Neves_1.pdf $>$. Acesso em: 17 jul. 2009.

NEVES, N. N. A.; NUNES, T. A.; RIBEIRO, M. C. C.; OLIVEIRA, G. L.; BENEDITO, C. P. Alelopatia do nim nos aspectos fisiológicos da germinação de sementes de maracujá em distintos períodos de armazenamento. Caatinga, Mossoró, v. 21, n. 4, p. 105-112, 2008.

PAIXÃO, M. F. Controle alternativo do gorgulho-domilho, Sitophilus zeamais, em armazenamento com subprodutos do processamento do xisto, no Paraná, Brasil. Revista Brasileira de Agroecologia, Bahia, v. 4, n. 2, p. 67-75, 2009.

PREVIERO, C. A.; NOBREGA, S. L.; FERNANDEZ, G. A. V.; MARANHÃO, N. P.; SAMPAIO, C. P. Avaliação do falso-açafrão na qualidade de sementes de milho (Zea mays L.) armazenado. In: CONGRESSO BRASILEIRO DE ENGENHARIA AGRÍCOLA, 35; JORNADA DE INICIAÇÃO CIENTÍFICA DO CEULP/ULBRA, 9., 2006, João Pessoa. Anais... João Pessoa: ULBRA, 2006. 
RUAS, R. A. L.; NASCIMENTO, G. B.; BERGAMO, E. P.; DAUR JUNIOR, R. H..; ARRUDA, R. G. Embebição e germinação de sementes de crambe (Crambe abyssinica). Pesquisa Agropecuária Tropical, Goiânia, v. 40, n. 1, p. 61-65, 2010.

RUPP, M. M. M.; CRUZ, M. E. da S.; SOUZA JUNIOR, S. P. de; FERREIRA, G. da S. S.; FERREIRA, R. B. Efeito inseticida da terra diatomácea em cevada armazenada. Revista Brasileira de Agroecologia, Bahia, v. 2, n. 2, p. 1135-1139, 2007.
SOUZA, G. P.; FILGUEIRA, M.; ROSENTHAL, R.; HOLANDA, J. N. F. Caracterização de material compósito diatomáceo natural (Characterization of natural diatomaceous composite material). Cerâmica, São Paulo, v. 49, n. 309, p. 40-43, 2003.

TUZMEN, N.; CANDAN, N.; KAIA, E.; DEMIRYAS, N. Biochemical effects of chlorpyrifos and deltamethrin on altered antioxidative defense mechanisms and lipid peroxidation in rat liver. Cell Biochem Funct, v. 26, n. 1, p. 119-124, 2008.

ZAYED, S. M. A. D.; FARGHALY, M.; ELMAGHRABY, S. Fate of 14C-chlorpyrifos in stored soybeans and its toxicological potential to mice. Food and Chemical Toxicology, Spanish, v. 41, n. 6, p. 767772, 2003. 